\title{
167. DUAS ESPÉCIES DE RHODYMENIA (RHODOPHYTA, RHODYMENIACEAE) NO ESTADO DA BAHIA, BRASIL
}

\author{
José Marcos de CASTRO NUNES
}

\begin{abstract}
Recibido el 10 de abril de 2007, aceptado para su publicación el 25 de septiembre de 2007
\end{abstract} Publicado "on line" en septiembre de 2007

Two species of Rhodymenia (Rhodophyta, Rhodymeniaceae) in the Bahia state, Brazil

Key words. Rhodophyta, Rhodymeniaceae, Rhodymenia, Bahia.

Palavras-chave. Rhodophyta, Rhodymeniaceae, Rhodymenia, Bahia.

O Estado da Bahia está localizado no nordeste brasileiro numa região tropical do litoral do Brasil, com alta diversidade apresentando a flora de macroalgas marinhas mais rica do Nordeste e a terceira do Brasil (Nunes, 2005). As Rhodophyta constituem o grupo mais diversificado, tendo sido referidos 237 espécies, a partir de amostras coletadas no mediolitoral e infralitoral.

Rhodymenia é um gênero amplamente distribuído no mundo com cerca de 54 espécies, ocorrendo principalmente em águas quentes, no infralitoral em profundidades de até $100 \mathrm{~m}$ (Guiry, 2007). Segundo Wynne (2005) são referidas para o litoral atlântico americano quatro espécies: Rhodymenia divaricata E.Y. Dawson, R. occidentalis Børgesen, R. pacifica Kylin e $R$. pseudopalmata (J.V. Lamour.) P.C. Silva. Para o Brasil é referida, a primeira e última espécie respectivamente (Guimarães, 2006; Nunes, 2005).

O gênero Rhodymenia foi descrito por Greville (1830) e caracteriza-se por apresentar talos com porção ereta ou prostrada, usualmente estipitado, originados por um disco basal ou formando estolões, ramos comprimidos, cartilaginosos, simples ou ramificados dicotomicamente, palmadamente ou irregularmente. Estrutura multiaxial, medula compacta, pseudoparenquimatosa. Gametófitos dióicos. Espermatângios em pequenos soros subapicais ou em grandes grupos sobre o talo, produzidos superficialmente pelas células apicais. Procárpico, ramos carpogoniais com três ou 4 células originadas por uma grande e multinucleada célula suporte, que também origina duas células auxiliares, gonimoblastos desenvolvendo-se externamente em 2-3 lobos. Cistocarpos semisféricos, grandes e salientes, ostiolados, originados apicalmente ou espalhados sobre o talo. Tetrasporângios cruciados, em soros subapicais, espalhados sobre o talo ou formando proliferações (Guiry, 2007).

Este trabalho tem como objetivo estudar e descrever as espécies de Rhodymenia que ocorrem no litoral baiano e integra o Projeto "Algas marinhas bentônicas do litoral da Bahia, Brasil" desenvolvido pela Universidade Federal da Bahia em parceria com a Universidade do Estado da Bahia.

As amostras foram coletadas no litoral baiano nos municípios de Camaçari, Prado e Santa Cruz de Cabrália. As coletas foram realizadas no mediolitoral em substrato rochoso e no infralitoral através de draga tipo Holme. O material coletado foi fixado em formol a $4 \%$, para que se procedesse ao 

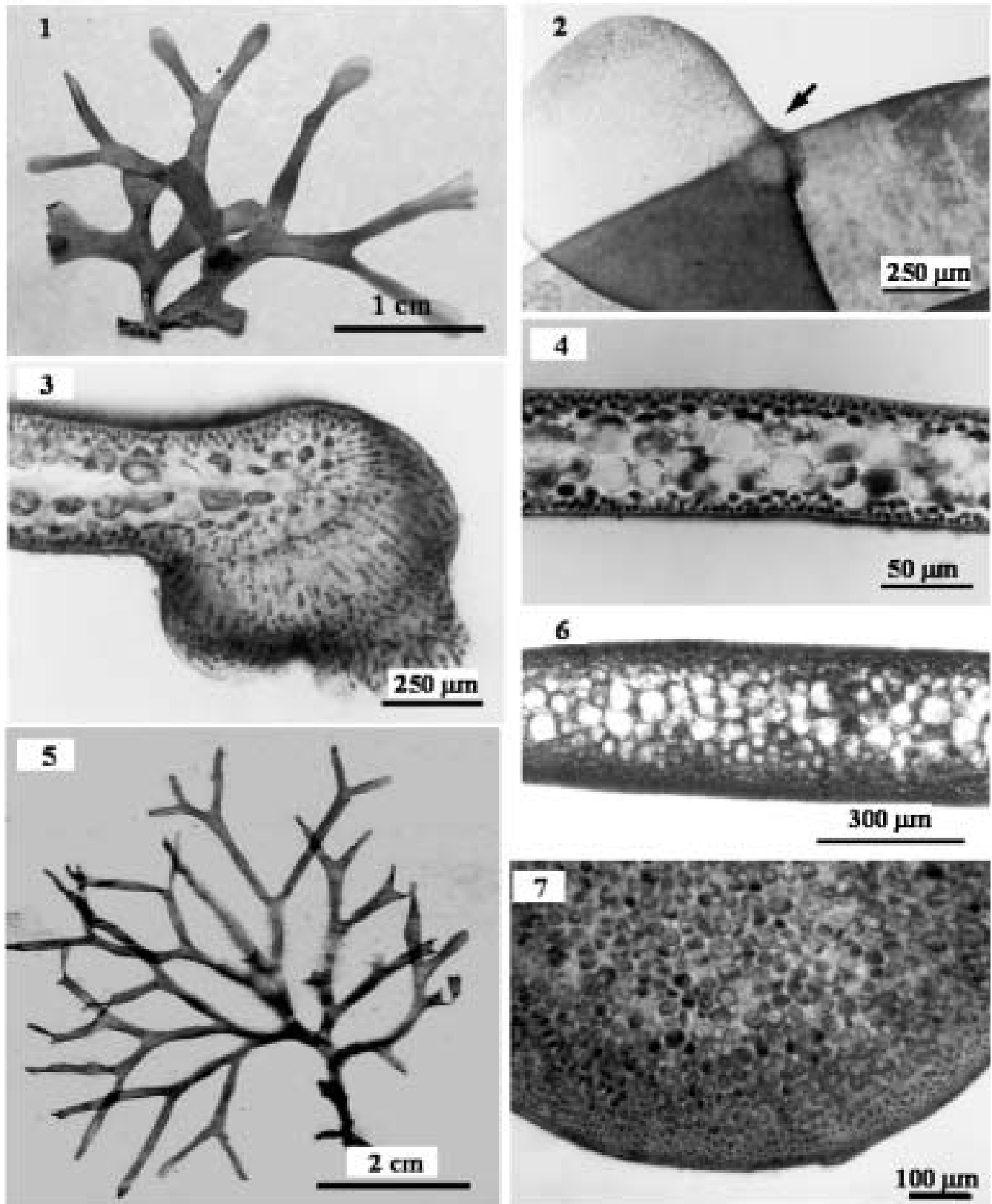

Figuras 1-4. Rhodymenia divaricata: 1: aspecto geral; 2: detalhe dos ápices dos ramos com anastomose (seta): 3: corte transversal na região com anastomose; 4: corte transversal do talo mostrando duas camadas de células medulares. Figuras 5-7. R. pseudopalmata: aspecto geral. 6: corte transversal do talo mostrando 4-5 camadas de células medulares; 7: corte transversal através do estipe. 
estudo anatômico. Exemplares depositados em herbário também foram estudados.

As espécies foram estudadas detalhadamente sob microscópio óptico, através de preparação de lâminas semipermanentes. Também foram realizados cortes histológicos manuais com auxílio de lâmina de barbear, corados com azul de anilina a $1 \%$, acidificada com $\mathrm{HCl} 1 \mathrm{~N}$. As fotografias foram feitas em fotomicroscópio com equipamento de captura de imagem (câmara Sony acoplada a microscópio Zeiss).

Após a identificação, descrição e ilustrações procedeu-se a montagem de exsicatas para inclusão no Herbário Alexandre Leal Costa (ALCB) da Universidade Federal da Bahia.

Chave artificial para identificação das espécies do gênero Rhodymenia para o litoral baiano.

1a. Talo sem estipe diferenciado, presença de anastomoses entre os ramos e 2 camadas de células medulares em toda a extensão da fronde R. divaricata

1b. Talo com estipe curto, anastomoses ausentes, 3-5 camadas de células medulares em toda a extensão da fronde

R. pseudopalmata

Rhodymenia divaricata E.Y. Dawson. Allan Hancock Pacific Exped. 3 (7): 141. 1941.

Figuras 1-4

Talo formando tufos róseoavermelhados, consistência firme, sem estipe diferenciado, medindo de 3-4 cm de altura, fixo ao substrato por pequenos apressórios discóides. Talo em forma de fita achatada, com 2-3 mm de largura, ramificação dicotômica irregular, ápices dos ramos espatulados. Estrutura pseudoparenquimatosa, em corte transversal com 120-150 $\mu \mathrm{m}$ de espessura próximo ao ápice, $140-170 \mu \mathrm{m}$ na porção mediana e 950-1.200 $\mu \mathrm{m}$ na base, com anastomoses entre os ramos. Região cortical com uma camada interna de células maiores, com 14-23 mm, e uma externa com células menores, com 4-11 $\mu \mathrm{m}$. Região medular com duas camadas de células grandes, incolores, da região basal ao ápice. Não foram coletados exemplares férteis.

Descrição e ilustrações adicionais: Dawson (1941): 141, pr. 23, fig. 31. e Schneider \& Searles (1976): 58-59.

Material examinado: Brasil, Bahia, Prado, Cumuruxatiba, J.M. de C. Nunes \& Lyra G.M., 10/03/01, (ALCB 53344); Santa Cruz de Cabrália, Y. Ugadim, 26/11/81, (SPF 9985).

Espécie com distribuição restrita ao litoral da Bahia e Espírito Santo. Primeira referência para o litoral nordestino.

Exemplares crescendo no mediolitoral, epilítica na região frontal do recife. Hospedeira de Ceramium comptum Børgesen. Associada a Amphiroa anastomosans Weber Bosse.

Dawson (1941) descreveu este táxon com base em exemplares estéreis de Sonora, México. Mais tarde Taylor (1945) encontrou exemplares estéreis na coleção de algas de Galápagos.

O hábito desta espécie é característico, formando tufos densos. Além do hábito típico, as plantas apresentam somente duas camadas de células na medula, o que as distingue de Rhodymenia pseudopalmata (J.V. Lamour.) P.C. Silva. Outra característica que separa $R$. pseudopalmata de $R$. divaricata é que na primeira, os soros de tetrasporângios são subapicais e, na segunda, estão espalhados pela fronde (Schneider \& Searles, 1991).

Os exemplares estudados diferem de Rhodymenia pseudohamata devido à presença de anastomoses entre os ramos, duas camadas de células medulares e ausência de estipe. Schneider \& Searles (1976) coletaram espécimes cistocárpicos e tetraspóricos na Carolina do Norte e do Sul, USA. Descrevem o cistocarpo como 
ostiolado, hemisférico, $750 \mu \mathrm{m}$ diâmetro, distribuídos na superfície do talo. Coletaram também, apenas uma planta tetraspórica com tetrasporângio cruciado, 16 × $25 \mu \mathrm{m}$, em soros irregulares nas porções superiores do talo.

Rhodymenia pseudopalmata (J.V. Lamour.) P.C. Silva. Univ. Calif. Publ. Bot.: 265. 1952.

Fucus pseudopalmatus J.V. Lamour. Dissert.: 29. 1805.

Figuras 5-7

Talos em tufos densos, vermelhovináceos, consistência firme, estipe cilíndrico pequeno. Porção estolonífera cilíndrica, com 230-350 mm de diâmetro. Talo em forma de fita achatada, com 3-5 cm de altura e 2-3 mm de largura, ramificação dicotômica. Estrutura pseudoparenquimatosa, em corte transversal com 250-350 $\mu \mathrm{m}$ de espessura na base e 150-250 mm no ápice. Região cortical com uma camada interna de células maiores, com 14-26 mm de diâmetro, duas externas de células menores, com 4-11 $\mu \mathrm{m}$ de diâmetro. Região medular com 3-4 camadas de células grandes incolores na região basal e 2-3 no ápice. Não foram coletados exemplares férteis.

Descrição e ilustrações adicionais: Cordeiro-Marino (1978): 79, fig. 200-202 (exemplares tetraspóricos).

Material examinado: Brasil, Bahia: 1248'945"S x 38¹0'090"W, 05/09/ 96, Cetrel, (ALCB 52808); Prado, Cumuruxatiba, J.M. de C. Nunes \& G.M. Lyra, 10/3/01, (ALCB 54444); Santa Cruz de Cabrália, Arakakaí, J.M. de C. Nunes \& G.M. Lyra, 09/3/01, (ALCB 53356, 53545, 61054); Paraíba, Praia do Poço, E.C.O.F., 18/ 12/88, (SPF 54989).

Espécie com ampla distribuição no litoral sul e sudeste do Brasil, nos estados do Espírito Santo, Rio de Janeiro, São Paulo, Paraná, Santa Catarina e Rio Grande do Sul.
Primeira referência para o litoral nordestino. Exemplares coletados crescendo no mediolitoral, epilítica na região frontal e protegida das formações recifais, no infralitoral a $23 \mathrm{~m}$ de profundidade. Hospedeira de Asparagopsis taxiformis (Delile) Trevis., Ceramium comptum Børgesen e Wrangelia argus (Mont.) Mont. Associada amphiroa anastomosans Weber Bosse, Anadyomene stellata (Wulfen in Jacq., Chondracanthus acicularis (Roth) Fredericq, Gelidiopsis variabilis (Grev. ex J. Agardh) F. Schmitz, Haliptilon subulatum (J. Ellis \& Sol.) H.W. Johans. e Laurencia oliveirana Yonesh.

AGRADECIMENTOS. Ao PICDT- CAPES pela concessão da bolsa de Pós-Graduação, à Empresa Ambiental CETREL por ter cedido material proveniente do infralitoral.

\section{BIBLIOGRAFIA}

CORDEIRO-MARINO, M. -1978-Rodofíceas bentônicas marinhas do Estado de Santa Catarina. Rickia 7: 1-243p.

DAWSON, E. Y. -1941- A review of the genus Rhodymenia with descriptions of the new species. Allan Hancock Pacific Exped. 3 (78): $123-153+12 \mathrm{pl}$.

GUIMARÃES, S. M. P. B. -2006- A revised checklist of benthic marine Rhodophyta from the state of Espírito Santo, Brazil. Boletim do Instituto de Botânica 17 145-194.

GREVILLE, R. K. -1830-Algae britannicae.pp. ixxxviii +218 .

GUIRY, M. D. -2007-AlgaeBase. World eletronic publication. Disponível em <http:// www.algaebase.com $>$. Acesso em: 06 de abr. $/ 2007$.

NUNES, J. M de C. 2005-Rodoficeas marinhas bentônicas do estado da Bahia, Brasil. Tese de Doutorado, Universidade de São Paulo. $410 \mathrm{p}$.

SCHNEIDER, C. W. \& R. B. SEARLES -1991- 
Seaweeds of the southeastern United States: Cape Hatteras to Cape Canaveral. Duke University Press. 553p.

TAYLOR, W. R. -1945- Pacific marine algae of the Allan Hancock expedition to the Galapagos Islands. Allan Hancock Pac. Exped. 12: 1-316.

WYNNE, M. J. -2005- A checklist of the benthic marine algae of the tropical and subtropical western Atlantic: second revision. Beiheft Nova Hedwigia 129:1-155.

Endereço do autor. Universidade Federal da Bahia, Instituto de Biologia, Departamento de Botânica, Laboratório de Algas Marinhas - LAMAR, Campus de Ondina, 40170-280, Bahia Brasil. jmcnunes@ufba.br ou jmcnunes2000@gmail.com

168. SOBRE EL STATUS DE PHYSALIS IXOCARPA BROT. EX HORMEN Eduardo SOBRINO VESPERINAS y Manuel SANZ ELORZA*

Recibido el 26 de enero de 2006, aceptado para publicación el 11 de noviembre de 2006 Publicado "on line" en febrero de 2007

On the status of Physalis ixocarpa Brot. ex Hormen

Palabras clave. Taxonomía vegetal, Solanaceae, Physalis.

Key words. Plant Taxonomy, Solanaceae, Physalis.

Tradicionalmente ha existido una seria controversia respecto al status taxonómico de Physalis philadelphica y Ph. ixocarpa; la primera de estas especies posee la flor y el fruto de mayor tamaño, pero las restantes caracteres morfológicos muestran fuertes afinidades. Aunque Fernandes (1970) apunta que las dos plantas son especies diferentes, basándose en las diferencias de tamaño de flor y fruto, Hawkes (1972) considera que existen dudas sobre la identidad de ambas. Ya anteriormente, Menzel (1951) las había agrupado, considerando Ph. philadelphica como sinónimo de Ph. ixocarpa, pero sin considerar la prioridad nomenclatural existente. El explorador y científico español Francisco Hernández (Hernández, 1651) había descrito, tan tempranamente como en el siglo XVII, dos tipos de tomatillo en Méjico, indicando además el nombre indígena, el de fruto grande, que denomina como tomate de cáscara, que de acuerdo con Hudson (1986) aparece actualmente en Méjico y Guatemala, y el tipo de fruto pequeño, que se encuentra presente en el sur de Méjico y también en Guatemala. En un principio, parece que este último se trataría de una forma silvestre, mientras que el de 